\title{
Estudo de impacto ambiental na escolha de tratamentos superficiais
}

\author{
Ciro Yoshiyasse ${ }^{1}$, Cosme Ribeiro ${ }^{2}$, Francisco Del Moral Hernández ${ }^{3}$, \\ Roberto Becker $^{1}$, Tatiane Bueno ${ }^{2}$ \\ Bosch $^{1}$, Henkel $^{2}$, Unesp/ $^{\text {Fatec }}{ }^{3}$ \\ ciro.yoshiyasse@br.bosch.com, cosme.ribeiro@henkel.com, prof.francisco@ @atec.sp.gov.br, \\ roberto.becker@br.bosch.com, tatiane.bueno@henkel.com,
}

\section{RESUMO}

O planejamento de projeto em Ecodesign envolve análises e decisões anteriores e posteriores ao campo de visão imediato ao projeto de produto: a visão anterior se dá nos meios de produção em relação aos materiais constituintes e a eficiência ambiental da tecnologia disponível, a visão posterior às funções do produto consumado está na destinação final, reciclagem e impacto do descarte de resíduos ao final da vida do produto. No presente trabalho analisaremos especificamente o tratamento superficial como parte desta "história do produto" com começo, meio e fim, coerentes numa unidade entre eficiência e responsabilidade pelo produto.

Os parâmetros deverão seguir especificações de resistência à corrosão da indústria automotiva, e deveremos avaliar e comparar o uso das principais alternativas de tratamento superficial utilizadas na atualidade: da pintura aos tratamentos galvânicos de deposição em suas principais opções comerciais.

Para tanto, se propõe avaliar indicadores de características ambientais e econômicas no sentido de melhorar a percepção com as quais são tomadas as decisões de projeto de produto. Em particular a importância de fatores diversos: a demanda de água, energia envolvida, custos, toxidade e destinação de efluentes e resíduos.

\section{Introdução: Ecodesign}

Este trabalho pretende contribuir na reflexão do projeto de Ecodesign na escolha de tratamentos de superfícies, e avaliar a inovação nanotecnológica no processo de fosfatização.

O produto da manufatura industrial é, em parte, resultado de um processo de captação e transformação de matéria e energia - Soma-se a isto, a circunstância do estado da arte da manufatura que no geral se foca no uso final do consumidor. No limite, estes elementos 
poderiam ser comparados a um evento complexo qualquer presente na natureza, como a fotossíntese que capta o gás carbônico, nutrientes e água, e que resulta em matéria orgânica e vida, que prossegue, cumpre suas funções, definha ao encontrar o limite de seu ciclo de vida, mas mantém viva a lei da conservação da massa (Lavoisier). No entanto, como evento físico e inserido nas leis da termodinâmica, a reprodução indefinida do processo fabril não é viável fisicamente no longo prazo - a entropia tende sempre a aumentar, cria-se mais desorganização no sistema, a recuperação energética nos processos é limitada. Hábitos e processos devem mudar se algum índice de sustentabilidade quiser ser alcançado. Esta "desorganização" acumulativa dos processos humanos resulta, por exemplo, em aumento exponencial da quantidade de rejeitos em aterros e no esgotamento das fontes de energia, que passaram historicamente do uso da madeira ao coque e, passando para o petróleo, urânio e para mais além, na direção do retorno às formas de energia ditas alternativas, mas originalmente foram as primeiras a serem utilizadas de forma rudimentar e em baixa escala, como a energia solar, biomassa, eólica etc. Ao impacto de uso de reservas minerais, florestas, e nos insumos como água e energia, soma-se à lista de "desorganização" do sistema, as doenças geradas pelo manuseio de elementos agressivos à vida. Os altos custos públicos de redução do desequilíbrio que foram e são grandes na recuperação somente parcial dos locais que serviram às atividades produtivas durante a Revolução Industrial na Europa e Estados Unidos, se deslocam hoje para a periferia onde até então originalmente estavam localizadas apenas as reservas de recursos naturais. Para reduzir o impacto neste nível, uma das melhores formas é observar, acompanhar, inventariar e gerenciar a destinação final dos produtos e rejeitos, ampliando-lhes possibilidade de reuso, de reciclagem mecânica, química e recuperação energética. E, por fim, o aterramento ou incineração, como último recurso.

O Ecodesign, ao lado das regulamentações legais de uso de recursos naturais e controle da poluição, tendem a se constituir como limites de ação de médio e longo prazo, na esfera privada e pública. As decisões de projeto são tomadas a partir de modelamentos de negócio são tomadas as decisões de projeto, portanto o domínio das questões de disponibilidade de fatores de produção (recursos naturais escassos) passa a ter, além de relevância técnica, protagonismo estratégico na esfera privada: obtém-se assim: know-how na prevenção de sanções legais cujas exigências podem ser progressivas e retroativas, capital simbólico de confiabilidade e redução de custos, como veremos no desenvolvimento que segue.

\subsection{Produtos: passivo ou ativo}

Uma abordagem quantitativa de consumo de recursos ao longo da cadeia de produção que resulta neste mesmo componente, mas é necessário ao mesmo tempo realizar a avaliação entre as diversas opções de tratamentos de superfície e a necessidade do mesmo, que é em si apenas o último recurso para evitar-se a corrosão com perda de função; também não se pode perder de vista a eficiência deste mesmo componente na economia de recursos realizados ao final da vida do automóvel.

Ashby[1] cita que os produtos devem ser divididos a princípio em dois grupos, de um lado os produtos industrializados que consomem ou intervém em algum recurso em energia ou massa durante o uso do produto, como um automóvel, lâmpada ou uma máquina agrícola (ativos). De outro lado estão os produtos que não serão avaliados em termos e eficiência energética ou de capacidade de utilização de recursos naturais, como uma cadeira ou outro objeto que não consuma energia e nem processe materiais (passivos). 
Neste segundo grupo busca-se otimizar na sua produção o consumo de recursos, ou seja - para um mesmo valor de uso da mercadoria, é necessário minimizar os recursos em termos de massa e energia embutidos no produto Um exemplo simples poderia ser uma cadeira cuja escolha deverá levar em conta a disponibilidade da matéria prima, o baixo consumo de energia no processo produtivo de processamento, a baixa toxidade em processo de produção e descarte,numa vez que, também os custos financeiros e de recursos materiais da reparação ambiental advinda do processo e do descarte são altos. Em estudo realizado para este mesmo fórum tendo como base a escolha de diversos materiais, sabe-se que todos estes fatores parecem convergir para indicadores comuns, em outras palavras: o consumo de água, energia, materiais coincide sempre com os custos econômicos. Em especial, o fator embodied energy revela-se como importante indicador para aferir uma aproximação ou afastamento dedo conceito de projeto ambientalmente amigável e econômico.

"Produtos passivos são os que não requerem muita energia para cumprir sua função primária (móveis, carpetes e acessórios, pontes, edifícios sem calefação); para esses, as fases de produção e manufatura dominam o consumo de energia $e$ materiais. Nesse caso, ampliar a vida útil do produto faz sentido; dobrar a vida útil de qualquer deles reduz quase à metade o consumo de recursos. Já vimos que, um móvel bem-desenhado, feito com materiais de qualidade, pode adquirir valor e desejabilidade com o tempo, e a sua vida útil ilimitada não tem consequências negativas para o sistema."

"Ao contrário, produtos consumidores de energia (eletrodomésticos, veículos, sistemas de calefação ou ar-condicionado) consomem mais recursos-acima de tudo, mais energia- na fase de utilização de sua vida útil do que todos os outros juntos (..). Então , o maior potencial de melhoria encontra-se no exame da utilização. Aumentar a vida útil de produtos que consomem energia, em particular daqueles que utilizam tecnologia que está mudando rapidamente, pode ser contraprodutivo por razões que já citamos. Em vez disso o foco está em materiais leves para reduzir o consumo de combustíveis em sistema de transporte, equipamentos eletrônicos mais eficientes, dotados de modo "stand-by" e "dormir" que interrompem o consumo de energia elétrica quando o produto está inativo, e materiais com melhor isolamento térmico para reduzir o desperdício de energia em geladeiras, freezers e sistemas de calefação. E, se a vida útil do produto é curta, reutilizá-los ou recicla-los oferece ganhos particularmente grandes.” [1]

Conclui-se com isto, que as condições de projeto para passivos estão intimamente ligadas ao menor valor representado pelo coeficiente entre massa e energia necessárias para consumar o produto. É claro que a circunstância de projeto determina a tecnologia disponível, o deslocamento de insumos e mercado e, ainda, condicionada por fatores governamentais. Consideremos, no entanto, que a circunstância de projeto se refere a um momento determinado, e que tende a reduzir fatores exógenos, uma vez que s sofre a ação da evolução natural dos mercados e da força renovadora das inovações.

Por outro lado, no primeiro grupo que podemos chamar genericamente de máquinas ativas, a prioridade está em aumentar sua eficiência, ou seja, maximizar o desempenho em termos de consumo, muitas vezes relacionado à redução de peso, 
até porque a redução de recursos necessários para concretizar o produto podem ser ínfimos em relação à quantidade de recursos que serão melhor aproveitados ao longo de seu ciclo de vida útil. No caso em discussão a abordagem primária quanto à meta de Ecodesign, será o consumo de combustível do automóvel a principal, uma vez que ao longo de sua vida pode vir a consumir muitas vezes o seu próprio peso em combustível sem que necessariamente tenha maximizado seu percurso ou sua capacidade de transporte de carga.

\subsection{Tempo}

Nos trabalhos do especialista em materiais Michael F. Ashby, o tempo de vida do produto é divido em várias categorias. De forma geral Ashby é adepto da leitura das relações indústria e meio ambiente baseadas em conceitos como embodied energy [2], que dialoga de certa forma com a compreensão dos processos nos termos da termodinâmica. O autor compreende as "vidas do produto" divididas em várias categorias [2]:

1.2.1 - Vida física do produto: que representa o período de tempo do produto após a quebra final, isto após último reparo possível

1.2.2- Vida funcional do produto: o período de tempo até que a necessidade do produto deixa de existir.

1.2.3 - Vida técnica do produto: representa o período de tempo até que , em função das mudanças tecnológicas, o produto se torna inaceitavelmente obsoleto.

1.2.4- Vida econômica do produto: é período de tempo em que um produto se torna não competitivo em função de oferta técnica e economicamente superior.

1.2.5- Validade do produto: período de tempo regido por normas, diretivas legislações ou restrições de validade.

1.2.6- Vida Comercial: período no qual o produto perde seu interesse em função da mudança de gosto, moda ou preferência estética.

Orientar o desenvolvimento de produto ao seu ciclo de vida ampliado é uma entre as escolhas de design de produto ambientalmente amigável. Talvez a mais complexa, porque se alimenta de diversas táticas, por assim dizer, convergindo para numa estratégia geral de produto inserido no contexto amplo além e aquém do restrito limite temporal de tempo das vidas útil e funcional do produto. No caso da indústria automotiva, a vida dos componentes do produto já está estabelecida em normativas próprias das montadoras de veículos. De forma geral, as discrepâncias de rigor, se tornam cada vez menores, uma vez que se enquadram beneficiam das nas mudanças tecnológicas do setor e que aprimoram gradativamente a qualidade dos tratamentos superficiais. 

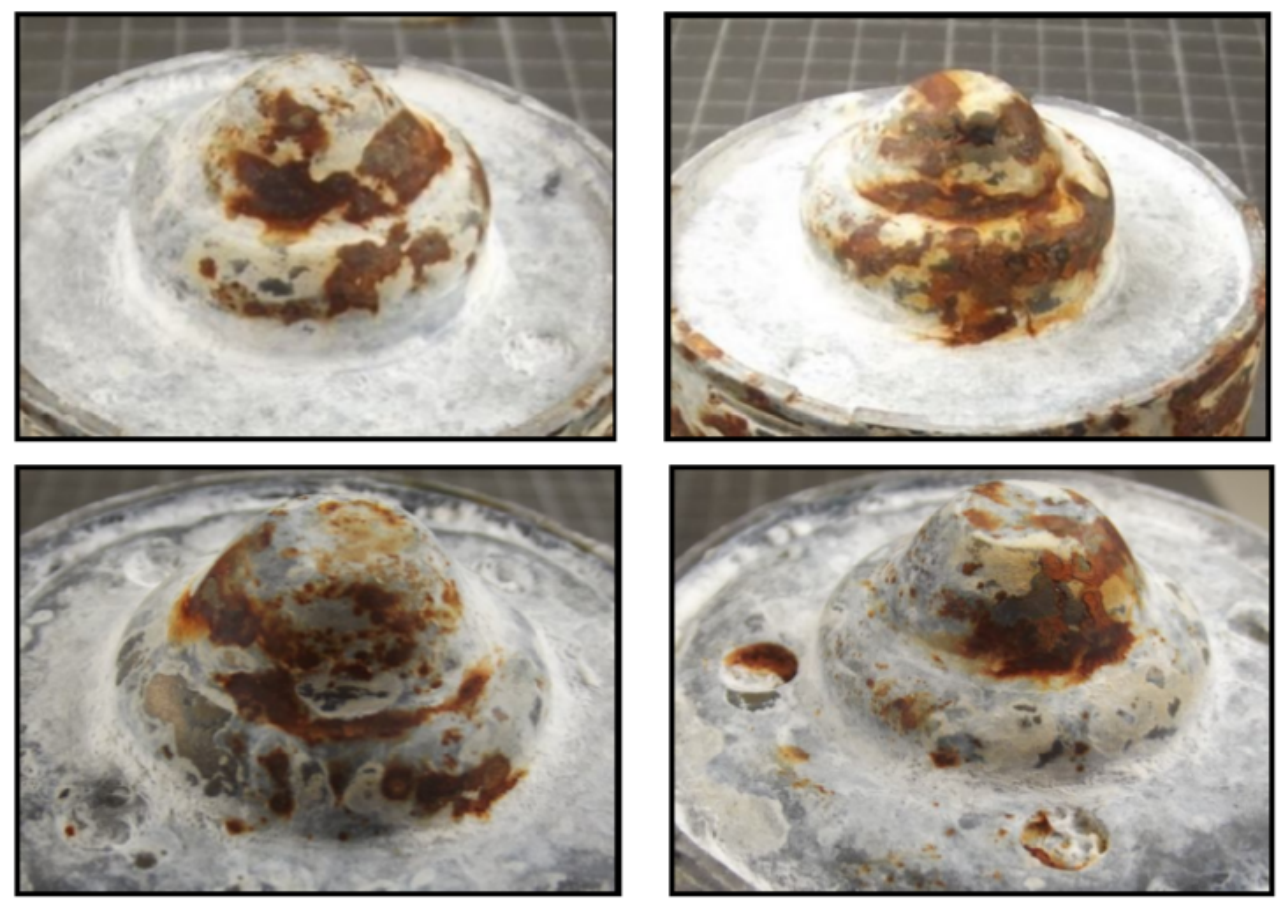

Fig 1: carcaça de motor zincada submetida a 200 horas de ensaio de salt-spray Formação de corrosão branca e vermelha.

Conforme especificação do cliente, as peças ensaiadas da figura 1 deverão resistir ao surgimento de corrosão vermelha após 120 horas de ensaio de névoa salina. Não há, no caso, uma descrição para o surgimento da corrosão branca. A previsão exata e a especificação ajustada ao uso reduz o desperdício econômico e ambiental.

Para introdução do tema dos tratamentos de superfície, o tempo de uso, ou o tempo de vida devem ser então estudados com a maior precisão possível, na medida em que a durabilidade do produto é exatamente o fator demandante das características de dimensionamento e seleção do tratamento de superfície.

\subsection{Inovação}

Este quesito demarca a ênfase na conhecida capacidade de reinvenção dos processos até então reconhecidos como solidamente instituídos, seja pela eficiência ou pelo preço. Este trabalho chama a atenção sobre a boa performance do nanocomposto na área de tratamentos de superfície que, de maneira geral, reduz o consumo de energia e a massa envolvida no processo. O mecanismo da inovação opera ofertas de tecnologias por vezes concorrentes, que gradativamente são apuradas e se combinam entre si, acumulando inovações em saltos quantitativos, nem sempre percebidos pelos atores envolvidos [3]. Para ilustrar um debate contemporâneo escolhemos a nanotecnologia que disputa o mercado de fosfatização, considerado um prétratamento superficial amplamente utilizado, consolidado e precursor de grandes transformações inovativas. 


\subsection{1- Nanotecnologia}

A nanotecnologia começou a ser discutida em 1959, pelo físico Richard Feymann em uma palestra no Instituto de Tecnologia da Califórnia. A nanotecnologia, ou tecnologia atômica, como também é conhecida, refere-se a uma gama de novas tecnologias que buscam manipular átomos, moléculas e partículas subatômicas para a criação de novos produtos [4].

Definem-se nanociência e nanotecnologia como pesquisas e desenvolvimentos tecnológicos no nível atômico, molecular e macromolecular na escala de 0,1 a 100 nanômetros. Um nanômetro equivale à bilionésima parte de um metro, a milionésimo de milímetro. Para efeitos comparativos, um fio de cabelo tem o diâmetro de aproximadamente 30.000 nanômetros. Já um átomo possui em média 0,2 nanômetros de diâmetro.

O comportamento dos materiais na escala nanométrica se difere da escala em que estamos familiarizados a lidar na indústria automotiva. Nessa escala, os átomos se revelam com características peculiares, por exemplo,_apresentando grande área superficial e, freqüentemente, com propriedades mecânicas, ópticas, magnéticas ou químicas distintas de aglomerados de partículas e superfícies macroscópicas.

Atualmente, estamos presenciando a transição do universo micrométrico, para o manométrico, mil vezes menor, para o qual o chip de grau eletrônico nos trouxe,. Não é exagero afirmar que, no universo nanométrico, todas as ciências se encontram. Átomos, moléculas e compostos tornam-se objeto de interesse tanto dos químicos como dos físicos, biólogos, engenheiros, cientistas de materiais, dentre outros.

Nesse universo, a física clássica começa a ceder lugar para a mecânica quântica, e assim muito da lógica e da observação tradicional não mais se aplicam [4].

Uma vez que a tecnologia baseia-se na funcionalidade dos materiais, a nanotecnologia implica_o conceito de nanomateriais, isto é, materiais em que a funcionalidade se restringe a um tamanho nanométrico. Em princípio, se fragmentássemos os materiais até seus limites, teríamos uma dispersão de nanopartículas, tão pequenas que se misturariam facilmente com um meio fluido, formando soluções coloidais, ou seja, soluções que contêm partículas de, no máximo, dois micrômetros, portanto invisíveis a olho nu [4].

A própria nanoescala confere às nanopartículas e nanomateriais uma enorme vantagem relacionada à maior área superficial disponível para a ação tecnológica. As nanopartículas proporcionam maior quantidade de átomos ou sítios ativos na superfície, intensificando a atividade de catálise ou de adsorção. 
Assim o portfólio de produtos que podem surgir é amplo variando desde os materiais nanoestruturados e nanocompósitos, aos dispositivos nanoeletrônicos.

A lista das empresas que já se envolvem com a nanotecnologia é muito grande e nela se incluem a DuPont, Dow, GE, Motorola, Exxon, Intel, Goodrich, Cabot, Xerox, Kodak, 3M, BASF, Siemens, Henkel, Degussa e das automotivas Volkswagen, Toyota, Daimler-Chrysler e General Motors. Há bastante espaço para o surgimento de empresas criadas pela transferência de tecnologia dos laboratórios de pesquisa, financiados com capital de risco. Esse tipo de iniciativa mostrou ser bastante eficaz nas últimas décadas e tem estimulado a pesquisa nos laboratórios do governo e das universidades a exemplo do Centro Nacional de Pesquisa em Energia e Materiais que abriga o LNNano - Laboratório Nacional de Nanotecnologia (Campinas, SP).

No Brasil, os esforços em nanociências e nanotecnologia são relativamente recentes. A primeira iniciativa oficial foi lançada pelo Conselho Nacional de Desenvolvimento Científico e Tecnológico ( $\mathrm{CNPq})$, com o programa de formação de redes de pesquisa, agregando pesquisadores de todo o País, interessados em nanotecnologia molecular e interfaces, nano biologia, materiais nano estruturados e nanodispositivos na área eletrônica.

\section{Tratamento de superfície, histórico de contaminações e nanopoluição :}

Especial atenção é dedicada à indústria de tratamento de superfície, em função de um passado ainda presente na memória e historicamente relacionado ao aparecimento de poluentes cancerígenos e letais, bem como o depósito precário e ilegal de rejeitos e contaminação por efluentes não tratados e relacionados às formas de contaminação mais conhecidas.

"Em 2002, a CETESB divulgou pela primeira vez uma lista de áreas contamindas do Estado de São Paulo, apontando a existência de 255 locais com problemas de contaminação em todo estado paulista. Desde então, a CETESB tem atualizando anualmente o registro de áreas contaminadas. Em seu último levantamento (2007), ela apontou a existência de 2.272 localizades contamindas." [5]

Soma-se à questão das contaminações o alerta sempre atual dos limitados recursos hídricos considerando que a galvanoplastia exige um consumo relativamente alto do recurso.

"Uma dessas contaminações foi detectada nas proximidades de Guararema (SP). O lençol freático da região foi contaminado com cádmio e só estará recuperado dentro de sete milhões de anos." [6]

"Há também os eventuais vazamentos acidentais de produtos químicos, que atingem córregos e rios, como aconteceu em 1996 na cidade de Caçapava (SP), onde foi detectado um vazamento de soda cáustica, que dizimou a fauna do rio Paraíba." [6]

No entanto, a galvanoplastia, possui sua vantagem comparativa em relação à economia de recursos naturais ao conferir maior durabilidade ao item industrializado diminuindo a frequência no aparecimento de falhas durante o uso, ou mesmo que o produto venha a perder 
o valor simbólico de projeto, induzindo uma nova aquisição e consequentemente maior consumo de recursos naturais e fatores de produção. Trata-se aqui de reduzir e neutralizar os efeitos nocivos resultantes do uso de produtos e processos críticos disponíveis, e que o são em função da grande tarefa empenhada pela galvanoplastia de enfrentar a inexorável ação do tempo, conferindo aos materiais menos nobres, características só encontradas entre os de maior custo, incluindo aqui o custo ambiental.

"Hoje no Brasil o custo em corrosão representa 3,5\% do PNB, o que equivale a US\$ bilhões por Ano. Nos Estados Unidos, conforme uma pesquisa realizada pelo Departamento de Transporte americano - Federal Higway Administration (FHWA)...o prejuízo causado pela corrosão em 1949 foi de 5,5 bilhões/ ano, em 1965 - 10 bilhões/ ano e em 1998 - 275,7 bilhões/ ano" [7]

A nanotecnologia inaugura simultaneamente à abertura da fronteira tecnologia outro conjunto de indagações que se referem ao campo da nanopoluição:

Em particular, nanopartículas e nanodispositivos podem constituir uma nova classe de poluentes cuja biodegradabilidade deve ser analisada. Tal como a poluição química de dimensões moleculares, as preocupações sobre a nanopoluição baseiam-se na persistência, bioacumulação e toxicidade de nanopartículas e outros produtos e nanoestruturas.

Nanopartículas e outras nanoestruturas serão consequentemente liberadas para o ar, solo e água na forma de - produtos que exijam algum grau de remediação ambiental seja através de fluxos de resíduos industriais e de laboratórios pesquisa seja como nanopartículas aderentes ou adsorvidas em produtos compósitos e particularmente após nanoprodutos serem descartados - sob a forma de nano-química pesticida e fertilizante; - por liberação acidental durante a manipulação ou transporte. Os impactos ecotoxicológicos de nanopartículas permanecem, sem dúvida, no estágio inicial de investigação e ainda insuficientemente compreendidos [9].

\subsection{Tipos de tratamento de superfície:}

A diversidade de tratamentos superficiais é ainda ampliada pelos graus de intensidade que podem ser aplicados, resultando em dimensionamentos especificos para cada uso. Na tabela I é possível avaliar certa quantidade destes tratamentos finais, muito embora não leve em consideração que os tratamentos superficiais são combinados entre si com o intuito de maximizar suas características e potencializar a adesão do processo. $\mathrm{O}$ objetivo da tabela é ilustrar os riscos ambientais relacionados em especial à toxidade. De forma geral é possível dizer que os tratamentos mais agressivos também tendem a ser mais eficientes na característica de proteção à corrosão, o que nos remete novamente à discussão sobre o conceito de produto "passivo" ou "ativo". É possível afirmar, por exemplo, que uma mudança de material e processo de tratamento superficial, que oferece um risco calculado ao ambiente, mas que permite reduzir consideravelmente o peso do automóvel, em outras palavras, aumentar a eficiência de consumo deste automóvel - possa ser utilizado com a perspectiva de que no ciclo de vida funcional da máquina este ganho contribuirá com a redução de emissões, e consumo energético de forma geral. 


\begin{tabular}{|c|c|c|}
\hline $\begin{array}{l}\text { Tratamento } \\
\text { superficial }\end{array}$ & Método & Risco ambiental [1] \\
\hline Serigrafia & $\begin{array}{l}\text { Utilizado em comunicação e decoração, basea-se se na } \\
\text { impressão de tela vazada sobre a superfície, a tinta é aplicada } \\
\text { por espátula sobre a tela vazada. }\end{array}$ & $\begin{array}{l}\text { Os produtos químicos, em particular os fluídos de } \\
\text { limpeza, podem ser voláteis e tóxicos e exigem boa ventilação } \\
\text { e proteção para o operador. }\end{array}$ \\
\hline Tampografia & $\begin{array}{l}\text { Utilizado em comunicação e decoração, utiliza a técnica } \\
\text { de transferência de tinta por almofada de silicone, que por sua } \\
\text { parte recebe a tinta de uma matriz rele vográfica. }\end{array}$ & $\begin{array}{l}\text { Solventes podem exalar vapores tóxicos, portanto, exige- } \\
\text { se ventilação. }\end{array}$ \\
\hline $\begin{array}{l}\text { Impressão por } \\
\text { transferência por } \\
\text { água (cubic } \\
\text { printing) }\end{array}$ & $\begin{array}{l}\text { Utilizado para impressão de películas decorativas e de } \\
\text { informação. A imagem é impressa em fina película solúvel } \\
\text { em água, dissolvida na água a imagem adere ao produto } \\
\text { imerso. }\end{array}$ & $\begin{array}{l}\text { Impressão por transferência não apresenta nenhuma } \\
\text { problema ambiental significativo }\end{array}$ \\
\hline Hot stamping & $\begin{array}{l}\text { Normalmente utilizada para decoração e impressão } \\
\text { metálica. A impressão a quente de matriz com folha impressa, } \\
\text { sobre o produto. }\end{array}$ & $\begin{array}{l}\text { Não é necessária nenhuma mistura de tintas ou limpeza } \\
\text { que envolva solventes orgânicos voláteis (VOCS). O processo } \\
\text { é isento de poluentes. }\end{array}$ \\
\hline $\begin{array}{l}\text { Decoração de molde } \\
\text { (IMD) }\end{array}$ & $\begin{array}{l}\text { Utilizado em larga escala sobre vasilhames plásticos, } \\
\text { também é utilizado para peças de acabamento. O processo é } \\
\text { baseado no estiramento de um filme de poliéster ou } \\
\text { policarbonato sobre a superfície do molde de injeção de } \\
\text { plásticos. }\end{array}$ & $\begin{array}{l}\text { I IMD está de acordo com os padrões restritivos da } \\
\text { indústria automotiva. Polímeros reciclados podem ser usados, } \\
\text { desde que não tenham nenhuma contaminação importante. A } \\
\text { resina do molde e a película podem ser do mesmo tipo de } \\
\text { material, o que aumenta o teor de reciclagem. }\end{array}$ \\
\hline $\begin{array}{l}\text { Metalização a vácuo } \\
\text { (PVD, physical } \\
\text { Vapor Deposition) }\end{array}$ & $\begin{array}{l}\text { Uso geral em peças plásticas, metálicas, cerâmicas de } \\
\text { acabamentos diversos. Uma fina camada de metal - } \\
\text { usualmente alumínio - é depositada por vapor sobre o } \\
\text { componente. O vapor ou névoa é criado numa câmara de } \\
\text { vácuo por aquecimento direto ou por feixe de elétrons do } \\
\text { metal e se condensa sobre a peça fria. }\end{array}$ & $\begin{array}{l}\text { Alto volume de produção, boa qualidade e limpeza - em } \\
\text { particular a ausência de produtos químicos desagradáveis - } \\
\text { tornam este processo atraente do ponte de vista comercial }\end{array}$ \\
\hline Eletrogalvanização & $\begin{array}{l}\text { Utilizado amplamente na indústria de forma geral para } \\
\text { proteção de produtos metálicos. Consiste na submersão da } \\
\text { peça (catodo) no eletrólito aquoso onde a corrente elétrica } \\
\text { impulsiona íons da fonte metálica (anodo) também submerso, } \\
\text { resultando numa fina camada de metal depositado sobre o } \\
\text { catodo. }\end{array}$ & $\begin{array}{l}\text { Muitos banhos de eletrogalvanização podem causar danos } \\
\text { ambientais e riscos para a saúde. Alguns contêm produtos } \\
\text { químicos desagradáveis - os que têm cianogênios são } \\
\text { absolutamente detestáveis. A proteção contra poluentes } \\
\text { químicos e vapores tóxicos requer preocupações especiais, } \\
\text { assim como o descarte do fluído de galvanização... }\end{array}$ \\
\hline $\begin{array}{l}\text { Galvanização } \\
\text { autocatalítica }\end{array}$ & $\begin{array}{l}\text { Quando o processo por eletrólise não é possível em } \\
\text { função da complexidade das superfícies internas da peça, em } \\
\text { geral a niquelação. Este processo é uma galvanização sem } \\
\text { eletricidade, a migração de íons ocorre em função da solução } \\
\text { aquosa, pela ação de um redutor presente na solução metálica } \\
\text { salina. }\end{array}$ & $\begin{array}{l}\text { É preciso enfrentar os problemas usuais do descarte de } \\
\text { resíduos químicos, porém, fora isso, o processo não é tóxico. }\end{array}$ \\
\hline Anodização & $\begin{array}{l}\text { Utilizado no Alumínio, que por ação da oxidação normal } \\
\text { confere a si uma película de óxido protetiva. A anodização } \\
\text { utiliza a peça como anodo, submersa em solução com catodo } \\
\text { inerte, forçando uma oxidação controlada que pode inclusive } \\
\text { ser colorida. }\end{array}$ & $\begin{array}{l}\text { Os produtos químicos envolvidos na anodização são } \\
\text { agressivos, porém manipuláveis. O descarte dos fluídos de } \\
\text { anodização usados requer um circuito de reciclagem. }\end{array}$ \\
\hline $\begin{array}{l}\text { Pintura a base de } \\
\text { solventes }\end{array}$ & $\begin{array}{l}\text { Utilizado amplamente na construção civil e objetos de } \\
\text { área extensa, além das impressões de todo tipo. Quando uma } \\
\text { fina camada de tinta é depositada, o solvente evapora } \\
\text { mantendo as resinas com os pigmentos em fina camada } \\
\text { protetiva e decorativa. }\end{array}$ & $\begin{array}{l}\text { Emissões originárias da evaporação dos solventes das } \\
\text { tintas à base de solventes (VOCs) são tóxicas, reagem a luz } \\
\text { sola e formam um nevoeiro e, em geral , são hostis ao meio } \\
\text { ambiente. }\end{array}$ \\
\hline $\begin{array}{l}\text { Pintura à base de } \\
\text { água }\end{array}$ & $\begin{array}{l}\text { Similar à pintura com solventes, porém o solvente é } \\
\text { água. As resinas livres da água, coalescem formando a } \\
\text { camada; }\end{array}$ & $\begin{array}{l}\text { Tintas à base de água reduzem emissões de VOCs e a } \\
\text { exposição dos trabalhadores a poluentes tóxicos e não } \\
\text { apresentam riscos de incêndio. Estão desbancando as tintas à } \\
\text { base de solvente, embora estas sequem rapidamente e } \\
\text { produzem um acabamento superficial melhor, com melhor } \\
\text { adesão. }\end{array}$ \\
\hline Pintura eletrostática & $\begin{array}{l}\text { Utilizado na indústria automotiva, em geral para peças } \\
\text { de única cor. A peça torna-se um catodo, o anodo é inerte e o } \\
\text { eletrólito é uma solução aquosa no qual o pigmento é } \\
\text { emulsificado. O ambiente alcalino conduz o pigmento para a } \\
\text { peça pelo campo elétrico formando a camada. }\end{array}$ & $\begin{array}{l}\text { O processo não apresenta nenhum risco particular ao } \\
\text { ambiente, além do descarte dos fluídos usados no banho. }\end{array}$ \\
\hline $\begin{array}{l}\text { Pintura eletrostática } \\
\text { a pó }\end{array}$ & $\begin{array}{l}\text { Aplicada sobre metais ou superfícies tratadas como } \\
\text { condutoras. O processo passa pelo aterramento da peça tendo } \\
\text { nos pigmentos em pó a cara negativa. Após a adesão da } \\
\text { camada, a peça é curada em forno. }\end{array}$ & $\begin{array}{l}\text { O processo não utiliza solventes e quase não libera } \\
\text { compostos orgânicos voláteis (VOCs), portanto, os operadores } \\
\text { não são expostos a altos níveis de toxidez. Poluição do a, riscos } \\
\text { de incêndio e compostos orgânicos voláteis são baixos. O } \\
\text { excesso de pó aspergido é reciclado. }\end{array}$ \\
\hline Esmaltação & $\begin{array}{l}\text { Utilizado em utensílios domésticos e decorativos cujo } \\
\text { material resiste à temperatura. Trata-se basicamente de } \\
\text { aplicação de vidro fundente com aglomerantes e agentes } \\
\text { corantes. }\end{array}$ & $\begin{array}{l}\text { O processo exige altas temperaturas, mas, fora isso, não } \\
\text { agride o meio ambiente. }\end{array}$ \\
\hline
\end{tabular}

Tabela I: tipos de tratamentos de superfície finais. 
Através do acúmulo de conhecimento da ciência ambiental, mesmo que de forma provisória, é possível identificar uma pré-seleção de processos menos agressivos que possam reduzir rejeitos, a presença de metais pesados, o alto consumo de água e energia.

\subsection{Escolha: tratamento superficial.}

Os tratamentos de superfícies conferem durabilidade aos produtos diante da ação dos diversos tipos de corrosão, seu objetivo original é a manutenção das funções do produto durante o tempo previsto para a vida do produto, levando em consideração que apenas excepcionalmente o material sem tratamento possue relativa resistência à ação de agentes degradantes e intempéries, sem que a este material seja necessário acrescentado alguma operação de proteção superficial. Materiais como certos plásticos, alumínio e metais nobres cuja oxidação e resistência à UV, por exemplo, não resulta em prejuízos significativos em massa ou outro atributo, como brilho, rugosidade etc.

Considerando a possibilidade do uso de material sem tratamento, temos dois exemplos de escolhas entre estratégias de materiais com e sem tratamento superficial.

\subsubsection{Exemplo A: parafuso em aço inoxidável e parafuso em aço liga zincado.}

No fluxograma proposto da figura 02 , para escolha de um produto metálico com tratamento e outra opção sem o tratamento para o caso analisado, avaliamos duas possibilidades: a construção de parafuso em aço inoxidável ou a construção deste mesmo produto em aço liga, com posterior tratamento superficial, condição típica para evitar a corrosão. Os comprimentos das setas representam os custos relativos das etapas do processo, coincidentemente estes custos são críticos em consumo de energia de processamento.

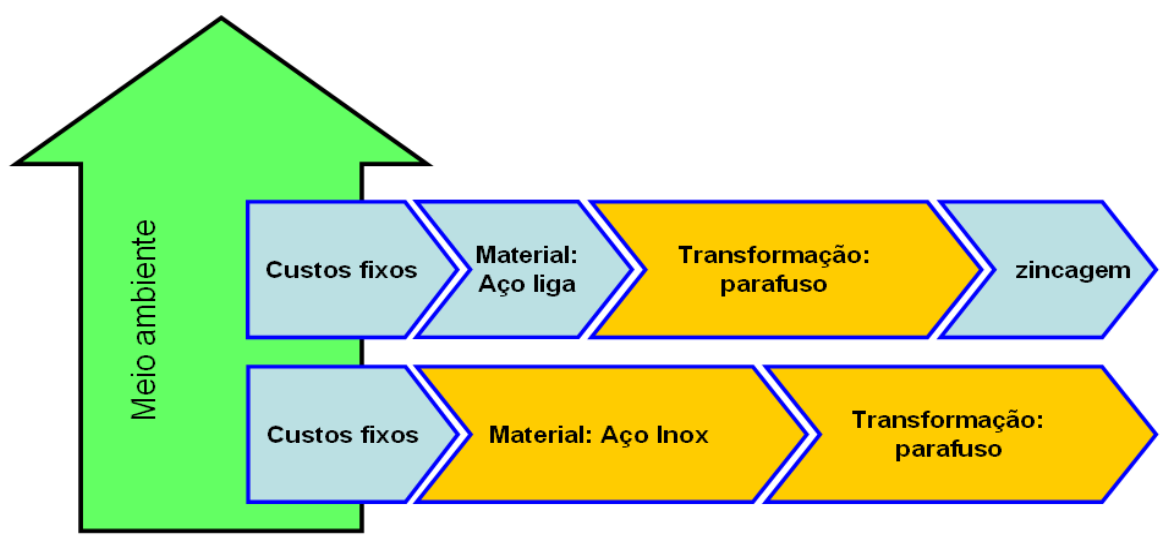

Fig. 02: parafuso em aço inox comparado ao parafuso em aço carbono zincado.

Como se vê na tabela II, os custos de processamento do Aço inoxidável impõe maior gasto em energia para a produção, resultando em maiores custos ambientais. Mesmo sem considerar o gasto energético em tratamento 
superficial( menos significativo se comparado ao a estes processos de alto consumo) a diferença se projeta no custo médio da própria matéria prima.

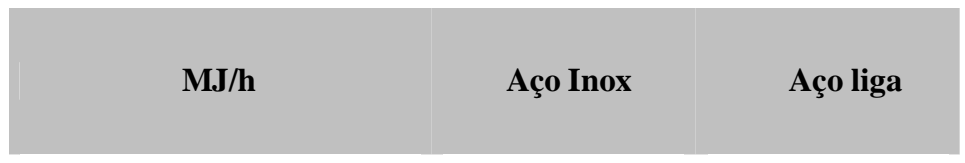

\begin{tabular}{|c|c|c|}
\hline Energia incorporada & 77 a 85 & 32 a 38 \\
\hline Energia de transformação & 3,0 a 3,7 & 3,2 a 3,9 \\
\hline
\end{tabular}
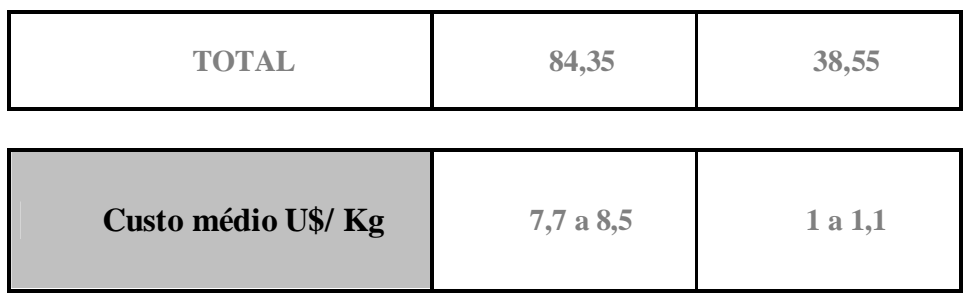

Tabela. II: parafuso em aço inox comparado ao parafuso em aço carbono zincado.

A unidade empregada denomina-se "energia incorporada", também traduzida como "conteúdo de energia" (embodied energy) [2], e representa a somatória de gastos energéticos para disponibilizar o material para posteriores transformações. Sua unidade é dada em Mega Joules por unidade de massa (g). Trata-se de um importante indicador ambiental que, aliado aos dados de energia necessária para a manufatura; deformação, fundição, injeção entre outros, capazes é capaz de fornecer dados estratégicos para comparação e escolha, no plano termodinâmico, do menor caminho em consumo de energia para a realização do produto - o que torna o projeto menos suscetível aos erros de diversas origens e às oscilações de mercado, porque representa $o$ balanceamento ótimo entre energia, massa e trabalho.

É possível indicar com certa margem de segurança que, neste caso, o tratamento superficial pode ser uma escolha ambientalmente correta.

\subsubsection{Exemplo B: maçaneta injetada em poliacetal ou injetada em liga de zinco revestida em cromo.}

Para este exemplo, teremos a grande capacidade de evolução e inventividade da indústria dos polímeros como aliado econômico. No caso, não apenas é possível cromar o polímero, obtendo resultados de mesma aparência ao metal, como também injetar o próprio material com aspecto metálico, embora com menor brilho. 
No fluxograma da Figura 03, os processos de alta energia são relativos à produção da liga de zinco e seu processamento, ainda que comparativamente à fusão de outros metais como o aço e alumínio, as ligas de zinco são relativamente menos dispendiosas em custo energético, mas representa, apesar disso, a metade dos custos energéticos de um material plástico. No entanto, em função de suas baixas densidades, os polímeros acabam por compensar o relativo alto custo por massa para superar o custo por unidade de volume. Exemplo: a liga de zinco utiliza $40 \%$ menos energia por $\mathrm{kg}$, no entanto possui peso específico três vezes maior.

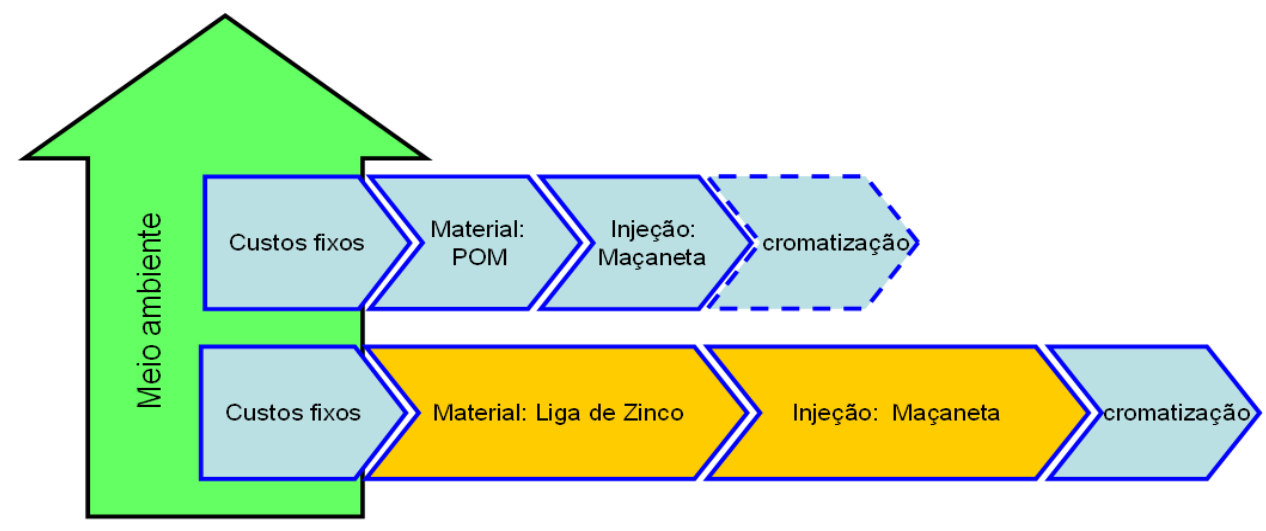

Figura 03: maçaneta em liga de zinco cromada comparada à maçaneta injetada em poliacetal na cor metálica (opção: cromatizada).

Comparando o balanço energético (Tabela III), convertendo-se MJ/ Kg para $\mathrm{MJ} /$ litro obteremos uma grande vantagem ao construir o produto em poliacetal, vantagem igualmente observada no custo do material, já convertido para valor em unidades de volume utilizado.

\begin{tabular}{|c|c|c|}
\hline $\mathbf{M J} / \mathbf{h}$ & liga de zinco & Poliacetal \\
\hline $\begin{array}{c}\text { Energia incorporada } \\
(\mathbf{M J} / \mathbf{K g})\end{array}$ & 70 a 75 & 115 a 121 \\
\hline Densidade (kg/litro) & 4,95 a 7 & 1,39 a 1,43 \\
\hline $\begin{array}{c}\text { Energia incorporada } \\
\text { (MJ/litro) }\end{array}$ & 433,19 & 165,79 \\
\hline $\begin{array}{l}\text { Energia de transformação } \\
\text { (MJ/ Kg) }\end{array}$ & 1,09 a 1,32 & 9,2 a 10 \\
\hline $\begin{array}{c}\text { Energia de transformação } \\
\text { (MJ/litro) }\end{array}$ & 0,20 & 6,83 \\
\hline
\end{tabular}




\begin{tabular}{|c|c|c|}
\hline TOTAL MJ/ litro & 433,39 & 172,62 \\
\hline
\end{tabular}

\begin{tabular}{|c|c|c|}
\hline Custo médio U\$/ kg & 3,09 a 3,4 & 2,7 a 4 \\
\hline Custo médio U\$/ litro & 19,39 & 4,71 \\
\hline
\end{tabular}

Tabela. III: maçaneta em liga de zinco cromada comparada à maçaneta injetada em poliacetal na cor metálica (opção: cromatizada).

Conclui-se através dos exemplos, que as escolhas de peças tratadas superficialmente e as opções de materiais que não necessitam de proteção superficial devem ser estudadas criteriosamente Também é possível compreender que a tendência de aumento de custo tende a ser reflexo de custos energéticos elevados. $\mathrm{O}$ conceito de energia incorporada para produção de cada material e desenvolvimento de processo pode servir como parâmetro de uso racional de massa e energia. Em outras palavras, a energia incorporada é um indicador ambiental muito interessante.

Deveremos, em seguida, refletir sobre qual abordagem poderia avaliar as estratégias contra a corrosão, entre elas os tratamentos superficiais comuns e, mais além, outras estratégias de uso de materiais não suscetíveis à corrosão.

\subsubsection{Pré-tratamento superficiais, o caso da fosfatização.}

A combinação de tratamentos é realizada em processo contínuo, ou em batelada onde se combinam várias ações de limpeza e remoção de resíduos. Destacadamente escolhemos a fosfatização como o processo de prétratamento superficial para uma avaliação. O Pré-tratamento de superfície tem como objetivo converter uma superfície metálica pela deposição química de um conversor de camada (Fosfato, por exemplo) e também serve como preparação para recebimentos de deposição orgânica, além de garantir por si só uma resistência a corrosão que o faz também ser considerado um tratamento final conferindo-lhe maior durabilidade do material.

A fosfatização é o processo mais utilizado na proteção de peças metálicas contra a corrosão. Essa proteção é realizada a partir da deposição de uma camada de fosfato sobre o metal, formando, assim, uma camada passiva que impede que o metal sofra um processo de corrosão. Isso é possível devido ao aumento da rugosidade do substrato, o que permite maior aderência da tinta protegendo a peça contra o intemperismo. É importante salientar que a fosfatização sem a pintura ou a pintura sem a fosfatização não apresentam resultados satisfatórios.

A figura 04 ilustra as várias formas de fostatização que, embora desenvolvidas já há muito tempo, ainda se mantêm em uso em casos específicos. A nanotecnologia surge em meados do ano de 2000. Alisaremos a fosfatização que utiliza a nanocerâmica. 


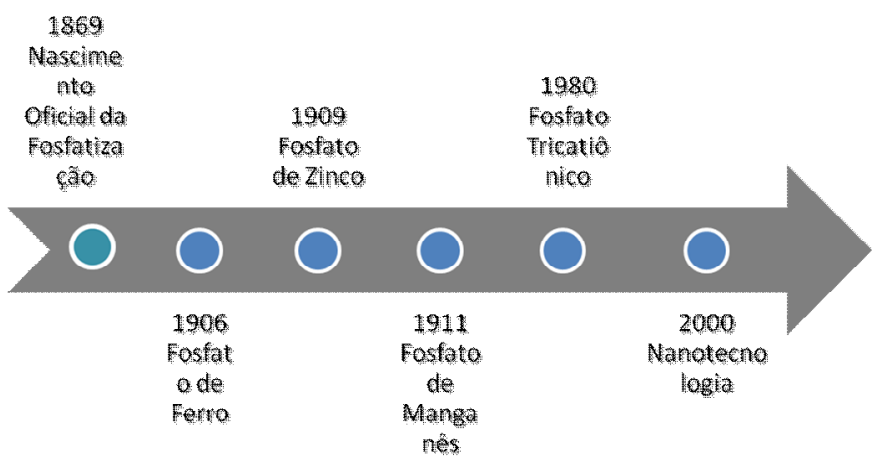

Figura 04: linha de tempo, do surgimento da Fosfatização ao surgimento de nanocompostos no processo.

\subsection{Nanotecnologia aplicada em tratamento de superfície}

Os dados que seguem a seguir foram coletados e observados em uma empresa que após muitos anos de utilização do processo convencional, optou poelo processo de fosfatização utilizando a nanocerâmica.

O tratamento de superfície convencional apresenta camada $\pm 2500 \mathrm{mg} / \mathrm{m}^{2}$, já o nanoceramico apresenta camada de aproximadamente $\pm 100 \mathrm{mg} / \mathrm{m}^{2}$. A figura 05 mostra diferença de camada Note-se a diferença entre as ampliações do microscópio de varredura (MEC) para cada composto.

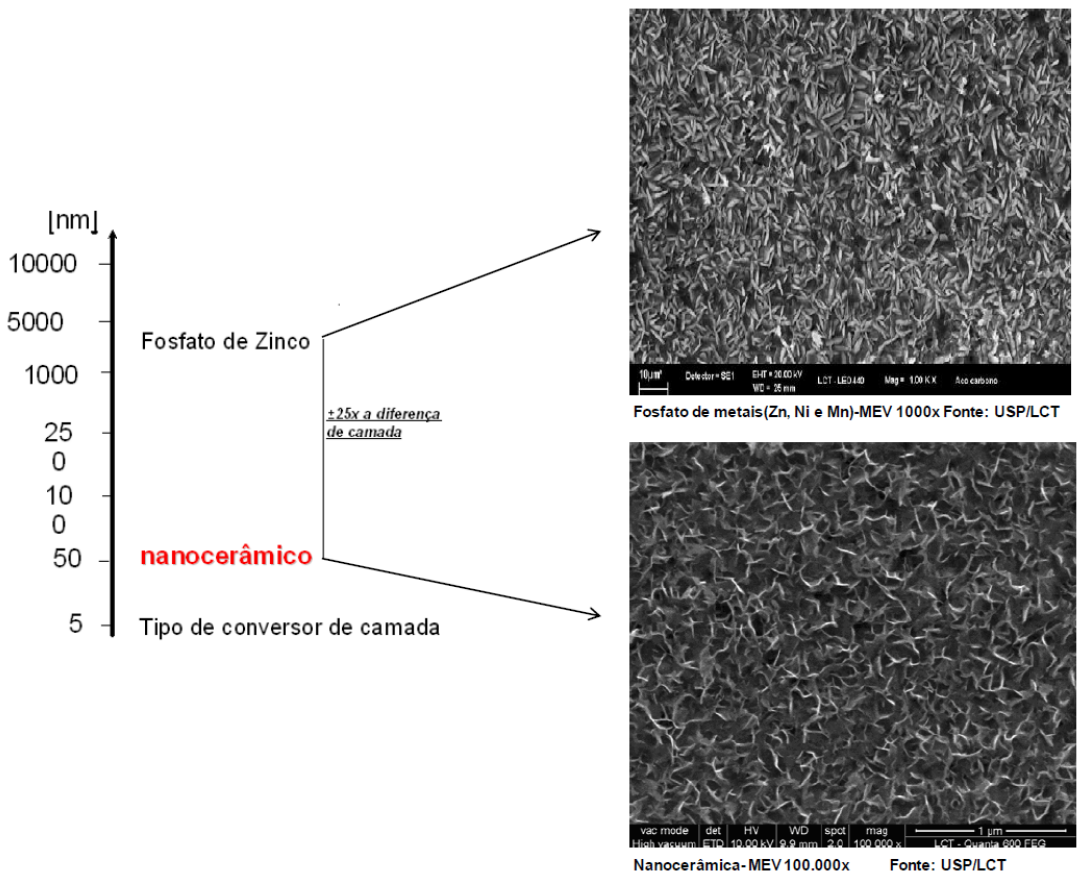

Figura 05: linha de tempo, do surgimento da Fosfatização ao surgimento de nanocompostos no processo. 
$\mathrm{Na}$ comparação de processos de fosfatização convencional e na de nanocerâmica é possível notar ${ }_{2}$ de imediato, as duas características: a redução do comprimento da linha e a redução da temperatura de banho. O que de imediato representa um impacto ambiental de redução de água e energia.

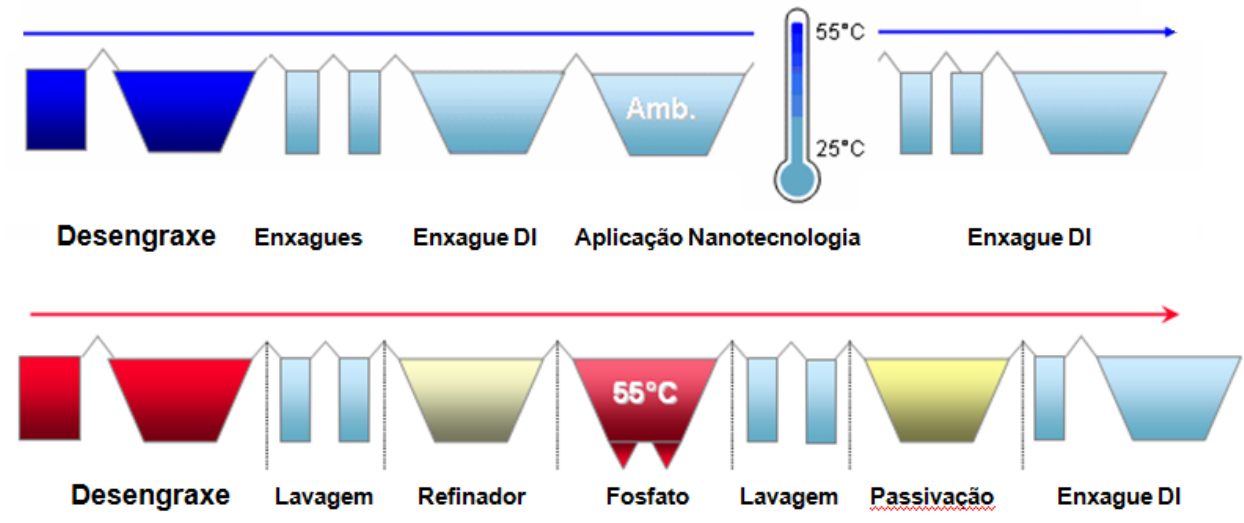

Figura 06: comparativo de processos: Fosfatização convencional e fosfatização com nonocompostos - queda de $55^{\circ} \mathrm{C}$ para $25^{\circ} \mathrm{C}$

$\mathrm{Na}$ comparação entre os processos apresentamos duas tabelas com a descrição dos processos em si Podemos inferir que os ganhos são ampliados e relacionados justamente à melhor das características difundidas da nanotecnologia: o redimensionamento das estruturas de materiais para uma escala nanométrica reduz a quantidade de material envolvido no processo de fosfatização reduzindo ao mínimo os rejeitos à base de fósforo que torna o processo bastante crítico em termos ambientais.

\section{Nanoceramic Fosfatização}

São isentos de fósforo, COD, BOD e metais pesados, o que reduz a complexidade e os produtos químicos destinados ao tratamento de efluente
Presença de metais pesados e fósforo, classificados como resíduos perigosos.

\begin{tabular}{lll|l} 
Não geram lama, não sendo mais & $\begin{array}{l}\text { Formação de lama de fosfato, } \\
\text { necessárias }\end{array}$ as limpezas químicas & aumentado os custos com tratamento
\end{tabular} aumentando a vida útil dos equipamentos. de resíduos.

Reduzem o consumo de energia e gás, Alto custo de energia e gás, pois para que o processo seja eficiente é necessário que o banho esteja aquecido a aproximadamente 55을

Reduzem o consumo de água, pois a contaminação nos estágios de lavagem é menor, tendo redução no nível de transbordo

Ganho de produtividade, pois é necessário apenas de 20 segundos para o tratamento
Alto consumo de água por causa das trocas constantes devido contaminações de estágios anteriores 
Ganho de produtividade com eliminação Uso de passivador e refinador, aumentando os custos com o de dois estágios: passivador e refinador. processo.

Tabela IV: comparativo de processos: Fosfatização convencional e fosfatização com nonocompostos.

Ao analisarmos o desempenho da empresa em questão, observa-se uma variação altamente significativa a favor da nova tecnologia. Os ganhos financeiros chegaram a $15 \%$ ao ano. Com a total eliminação de borra de fosfato.

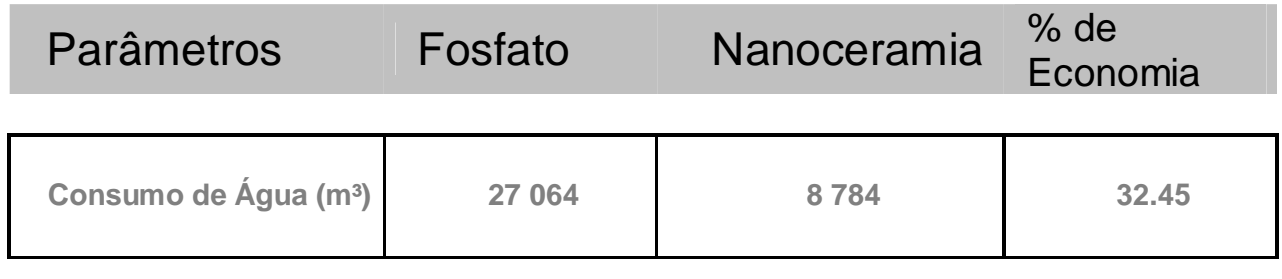

\begin{tabular}{|c|c|c|c|}
\hline $\begin{array}{c}\text { Consumo de produtos } \\
\text { químicos }(\mathrm{Kg})\end{array}$ & 80640 & 56400 & 69.93 \\
\hline
\end{tabular}

\begin{tabular}{|l|l|l|l|}
\hline Consumo de gás $\left(\mathrm{m}^{3}\right)$ & 77848 & 62278 & 80.00 \\
\hline
\end{tabular}

\begin{tabular}{|c|c|c|c|}
\hline $\begin{array}{c}\text { Consumo de Energia } \\
\text { Elétrica (Kw/h) }\end{array}$ & 552245 & 429000 & 77.68 \\
\hline
\end{tabular}

\begin{tabular}{|c|c|c|c|}
\hline $\begin{array}{c}\text { Tratamento de borra } \\
\text { de fosfato }(\mathrm{R} \$)\end{array}$ & 1020 & 0 & 100 \\
\hline
\end{tabular}

Tabela V: comparativo de processos: Fosfatização convencional e fosfatização com nonocompostos.

Os testes de durabilidade realizados apontaram para um desempenho positivo em relação ao teste de Salt Spray conforme norma ASTM B-117 em Laboratório: 1000 horas sem pontos de corrosão.

O desempenho medido da fosfatização em teste de Salt Spray está conforme norma ASTM B-117 em Laboratório: 500 horas sem pontos de corrosão.

Devemos considerar que a camada de conversão não pode ser avaliada individualmente. Nota-se na figura 07 , que as peças sofreram pintura posterior para avaliar a resistência do sistema completo. Vale ressaltar que, para o esse processo, 500 horas de Salt-Spray já indicam aprovação da peça. Não foi observada nenhuma alteração em resultados entre os dois processos de fosfatização e pintura. 


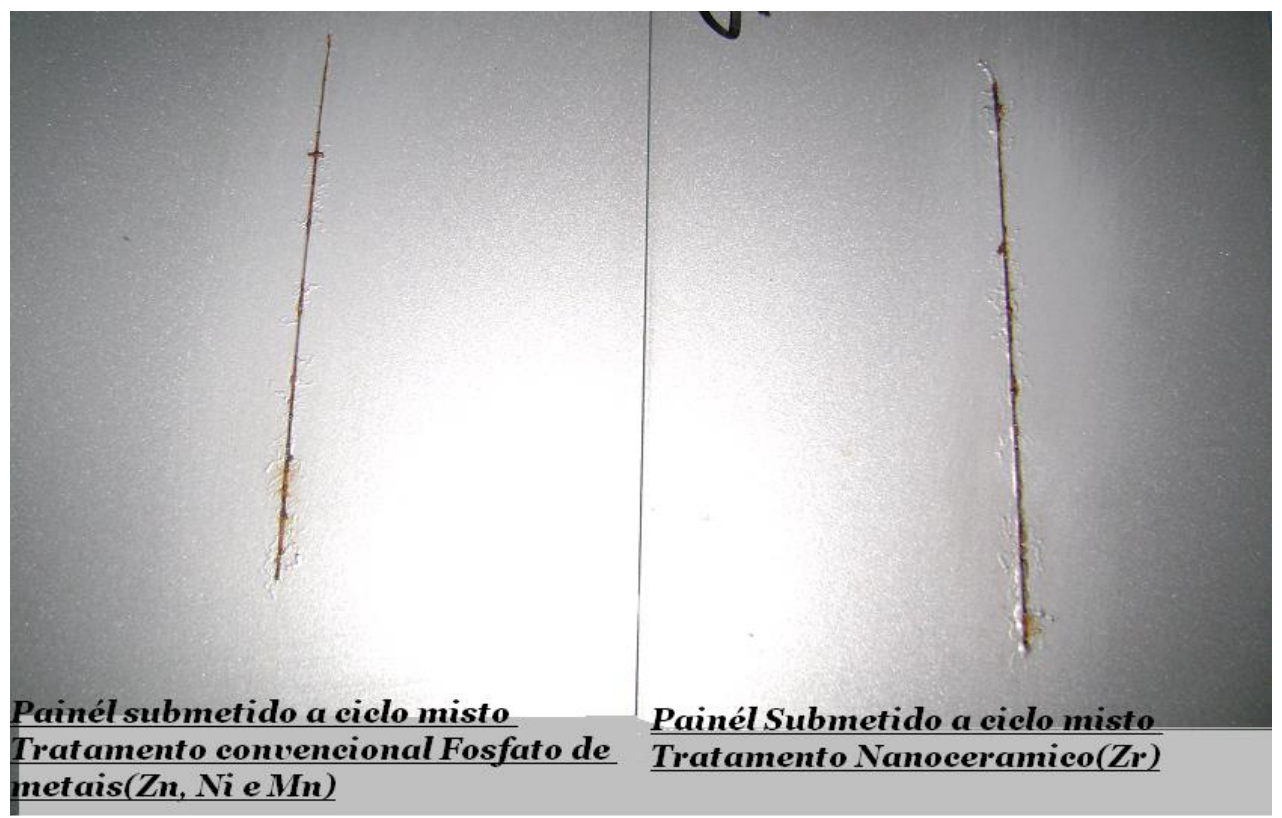

Figura 07: Compartivo de testes entre: Fosfatização convencional e fosfatização com nonocompostos.

Importante observar que as aplicações do produto em questão foram realizadas em uma empresa dedicada à chamada "linha branca" de eletrodomésticos, onde a prática de utilização de nanotecnologia já se dissemina, aliás por onde inclusive foi iniciada. Embora no Brasil, o tratamento superficial em automóveis já tenha sido homologado e praticado numa planta fabril e que por razões outras foi desativada, existe ainda certa inércia tecnológica e produtiva ainda a ser superada.

\section{4- Conclusão.}

Uma das maiores dificuldades das ciências ambientais reside na falta de indicadores e diagnósticos consensuais na comunidade e junto aos governos. O Ecodesign reflete este debate, e o exemplo disso é a dificuldade de se eleger prioridades entre as estratégias de desenho ambientalmente amigável. O tratamento de superfície deveria ser capaz de conferir novas características a um produto, fazendo com que qualidades específicas na maior parte das vezes com ganho de durabilidade, custo, resistência, aparência e principalmente de recursos naturais. No entanto as escolhas ambientalmente amigáveis travam necessariamente um diálogo com várias circunstâncias e demandas distintas que ainda se alteram nas visões de curto, médio e longo prazo. A proposta deste trabalho foi então, apresentar duas perspectivas aparentemente opostas em evolução: o uso do indicador embodied energy, ou a energia incorporada a um produto, como indicador de projeto sustentável numa visão que se baseia no balanceamento de massa, energia e função. Por outro lado, para o contraste escolhemos a nanotecnologia como onda geradora de soluções e quebra de paradigmas. 


\section{REFERÊNCIAS}

[1] ASHBY, Michael F.; JOHNSON, Kara. Materiais e design: arte e ciência da seleção de materiais no design de produto. Rio de Janeiro: Elsevier, 2011.

[2] ASHBY, Michael F. Materials and the Environment: Eco-Informed Material Choice. Oxford: Butterworth-Heinemann, 2009.

[3] ROSEMBERG Nathan. Por dentro da Caixa Preta. Campinas: Editora Unicamp, 2006.

[4] TOMA, Henrique E. O mundo nanométrico: a dimensão do novo século. São Paulo: Edusp, 2009.

[5] SPIRO, Thomas G.; STIGLIANI, William M. Química Ambiental: São Paulo: Pearson, 2008.

[6] VOJCIECHOVSKI, André Luiz; ... Curso de tratamentos de superfícies. São Paulo: ABTS, 2005.

[7] VALENZUELA, Julio. Tratamento de Efluentes em Indústrias Galvanotécnicas. São Paulo: Páginas \& Letras, 1999.

[8] SCRINIS, G. Nanotechnoloy and the environment. Chain Reaction no 97, Junho 2006 